\title{
Pleomorphic Lipoma - A Report of Two Cases
}

\author{
Jadhav.Meena N. ${ }^{1}$, PatilRashmi K. ${ }^{2}$, Kittur S.K. ${ }^{3}$
}

${ }^{1}$ Associate professor, Department of Pathology, Belagavi Institute of Medical Sciences, Belagavi.

${ }^{2}$ Associate professor, Department of Pathology, Belagavi Institute of Medical Sciences, Belagavi

${ }^{3}$ Professor\& Head, Department of Pathology, Belagavi Institute of Medical Sciences, Belagavi

\begin{abstract}
Pleomorphic lipoma is an uncommon benign lipomatous tumor predominantly seen in the dermis or subcutis of posterior neck, upper back and shoulders. Microscopically it is composed of mature adipocytes, pleomorphic multinucleated giant cells and thick collagen bundles. Prognosis is excellent with conservative excision. It is often mistaken for malignant tumors leading to unnecessary extensive surgery. Hence, awareness of this entity with clinical correlation are important for accurate diagnosis. Herein, we present two cases of pleomorphic lipoma presented as a mass in the nape of the neck.
\end{abstract}

Key words: Pleomorphic lipoma, spindle cell lipoma, floret - like giant cells.

\section{INTRODUCTION:}

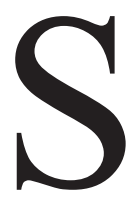

hmookler and Enzinger first described pleomorphic lipoma (PL) in 1981 in a series of 48 cases. ${ }^{1}$ It shows many similarities to spindle cell lipoma (SCL) which was originally described as a distinct entity by Enzinger and Harvey in 1975 . $^{2}$ These two tumors display an overlapping clinical, histological, immunohisto chemical and cytogenetic features. Hence, they are considered as one entity. ${ }^{3}$ They account for $1.5 \%$ of all adipocytic tumors. ${ }^{3}$

PL is more commonly seen in men between 50-70 years. ${ }^{4}$ It is predominantly seen in the dermis and sucutis of posterior neck, back and shoulders. ${ }^{1}$ Rarely it involves palm, tonsillar fossa, orbit, tongue, vulva, oral cavity. ${ }^{5,6,7}$ and retropharyngeal space. $^{3}$ It can pose diagnostic challenge in view of bizarre pleomorphic tumor cells on histology.

\section{CASE REPORT}

\section{Case-1:}

A female patient aged 35 years was admitted with history of painless swelling at the nape of the neck of two years duration. A clinical diagnosis of lipoma was made and the mass was excised. On gross examination the mass was yellowish, capsulated measured 5 X 4 X $1.5 \mathrm{~cm}$ with yellowish white cut surface. Microscopy showed capsulated tumor composed of intimate admixture of mature adipocytes, spindle cells, pleomorphic multinucleated giant cells and collagen bundles (Fig1). The spindle cells were uniform with hyperchromatic nuclei. At places floret - like giant cells were seen characterized by multiple, pleomorphic, hyperchromatic nuclei, indistinct nucleoli arranged in peripheral wreath- like fashion around dense cytoplasm. There was no mitosis or necrosis or plexiform capillary network. Mild lymphocytic infiltration was seen at places. Few mast cells were also seen (Fig 2). 
Fig 1. Microphotograph showing mature adipocytes and pleomorphic giant cells (H\&E, $X$ 200) in case 1. Inset: Gross photograph of a same tumor with yellowish white cut surface.

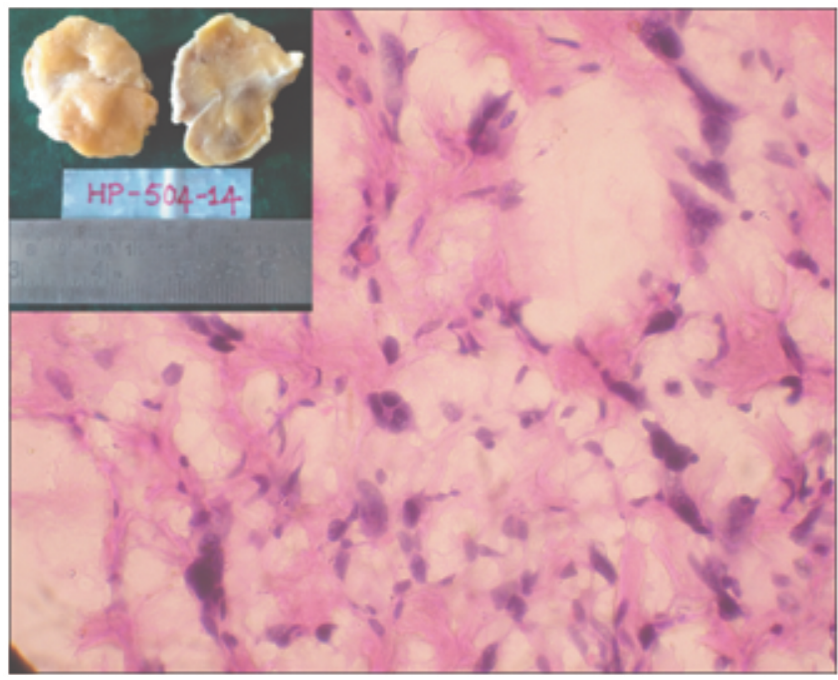

Fig 2. Microphotograph showing floret - like giant cell and collagen bundles in case 1 (H\&E, X 400).

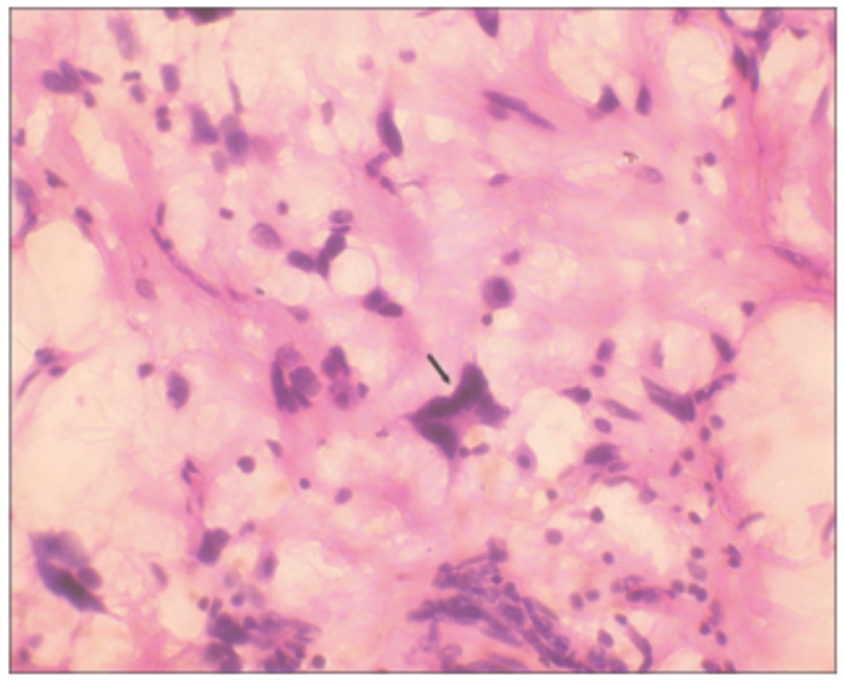

\section{Case 2:}

A 42 year old male patient was admitted to the hospital with history of painless swelling in the nape of the neck of five years duration. The mass was excised on clinical diagnosis of lipoma. Grossly the mass was globular, yellowish measured 7.5 X 6 X $3 \mathrm{~cm}$ with homogenous yellowish greesy cut surface. Microscopy showed predominantly mature adipocytes admixed with pleomorphic multinucleated giant cells. Few floret - like giant cells were also seen (Fig 3). There were no atypical spindle cells. Collagen bundles were sparse. Many mast cells were also seen. There was no mitotic activity or necrosis or lipoblasts.

Immunohistochemistry (IHC) was done in both the cases. The atypical spindle cells and multi nucleated giant cells (floret cells) showed diffuse strong positivity for CD 34 (Fig 4). They were negative for S-100 protein.

Fig 3. Microphotograph showing mature adipocytes and pleomorphic giant cells in case 2 (H\&E, X 200). Inset: Gross photograph of a same tumor with yellow cut surface.

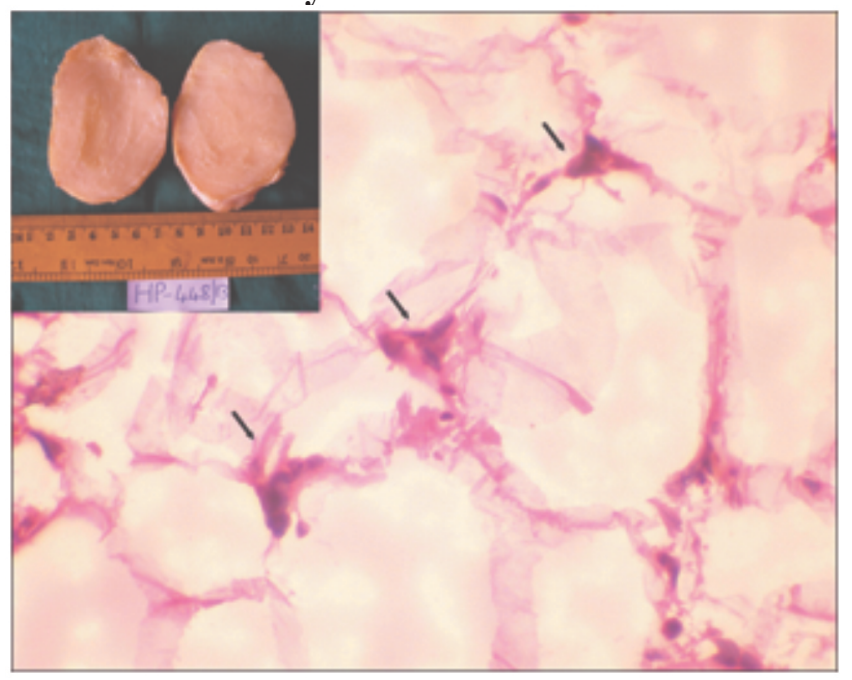

Fig 4. Microphotograph showing immunoreactivity of multinuecleated giant cells and spindle cells for CD 34 in case 1 (4a) and in case 2 (4b) (IHC, X 400).

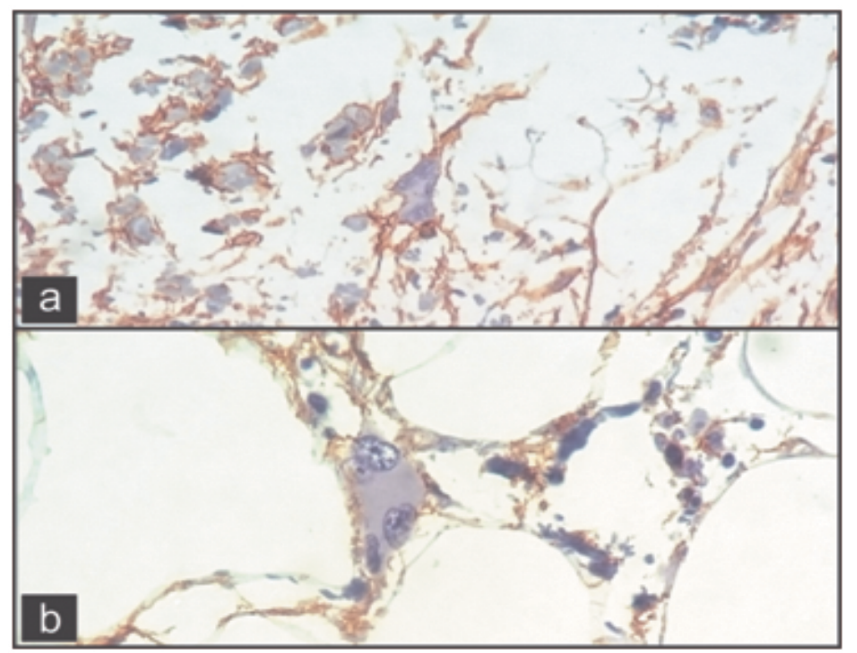


Based on these a diagnosis of PL in the nape of the neck was made in case 1 and case 2 . There was no evidence of recurrence or metastasis on three years of follow up in both the cases.

\section{DISCUSSION:}

PL is a typically slow growing mobile, solitary ,subcutaneous mass usually less than $6 \mathrm{~cm}$ in greatest dimention. ${ }^{1}$ Intradermal origin of the tumor is also reported which presents with district features like female predilection, wide anatomical distribution and infiltrative margins. ${ }^{3} \mathrm{PL}$ and SPL were grouped as 'atypical lipoma' by some authors, but now it is considered as a district entity from atypical lipomatous tumor / well differentiated liposarcoma (ALT/WDLS). ${ }^{8} \mathrm{SCL}$ and PL have same genetic aberrations like deletions of 16q13 qter or partial loss of chromosome 13 and or 16.5 On IHC, the spindle cells and floret - like giant cells are strongly positive for CD 34 but negative for S 100 protein and smooth muscle actin.,

The histogenesis of this group of tumors is uncertain. ${ }^{1,10}$ There are many hypotheses to explain their origin. They are considered as variants of lipoma. ${ }^{1}$ The spindle cells in lipomasrepresent immature mesenchymal cells possibly arrested at a very early stage of development to mature adipocytes which are capable of only collagen synthesis but lack the ability to store fat, but reason for pleomorphic or multinuclear morphology is unknown. $^{10}$ They have been thought to represent degenerated end stage of spindle cells. ${ }^{1}$ Endocrine, hereditary and topographic factors may play a role for the growth of the tumor. ${ }^{10}$
Microscopically they show wide histological spectrum depending on the proportion of cellular components. In the present study case 1 showed predominantly spindle cells, giant cells with few adipocytes whereas case 2 showed mainly mature adipocytes with few giant cells and sparse spindle cells. PL may lack mature fat content which may pose diagnostic challenge. ${ }^{5,9}$

The differential diagnosis includes ALT/WDLS, ${ }^{6,7}$ sclerosing liposarcoma, ${ }^{1}$ pleomorphic liposarcoma $^{1,7}$ myxoidliposarcoma ${ }^{4,5}$ myxoid variant of $\mathrm{MFH}$, giant cell fibroblastoma, and pleomorphic hyalinizing angiectatic tumor. ${ }^{5}$

ALT/WDLS is commonly seen in the deep soft tissues of extremities and retroperitoneum. Unlike PL it shows lipoblasts, marked atypia, absence of collagen bundles. ${ }^{6,7}$ and typical presence of giant marker and ring chromosomes on chromosomal analysis. Sclerosing liposarcoma mimicks PL but it has large areas of delicate collagen deposition, more number of lipoblasts and less multinucleated giant cells. ${ }^{1}$

Plemorphic liposarcoma can be differentiated from PL by its location in extremities and retroperitoneum, highly cellular pleomorphic cells, numerous lipoblasts and rare floret cells. ${ }^{1}$ Myxoidliposarcoma can be confused for PL but it is common in the extremities, show typical lipoblasts and rich plexiform vascular network. ${ }^{4,5}$

Dispite its pleomorphic appearance, PL does not recur or metastasize if completely excised. Hence, awareness of this entity with correlation of clinicopathological features helps in accurate diagnosis and thus helps to avoid unnecessary work up and radical surgery. 


\section{REFERENCES:}

1. Shmookler BM, Enzinger FM. Pleomorphic lipoma: A benign tumor simulating liposarcoma. A clinicopathologic analysis of 48 cases. Cancer 1981; 47(1): 126-33.

2. Enzinger FM, Harvey DA. Spindle cell lipoma. Cancer 1975; 36:1852-59.

3. Lee HK, Hwang SB, Chung GH, Hong KH, Jang KY. Retroperitoneal spindle cell / pleomorphic lipoma. Korean J Radiol 2013; 14(3): 493-96.

4. Sakhadeo U, Mundhe R, DeSouza MA, Chinoy RF. Plemorphiclipoma; A gentle giant of pathology. J Cytol 2015; 32(3):201-03.

5. Wang L, Liu Y, Zhang D, Zhang Y, Tang N, Wang EH. A case of 'fat free' pleomorphic lipoma occurring in the upper back and axilla simultaneously. World Journal of Surgical Oncology 2013; 11:145 DOI:10.1186/14777819-11-145
6. Singh N, Dabral C, Singh PA, Singh M, Guptaz SC, Jain S. Pleomorphic lipoma of the tonsillar fossa - a case report. Indian J PatholMicrobiol 2003;46(3):476-77.

7. Girian SS, Captain I. Pleomorphic lipoma masquerading as malignant neoplasm. International Journal of Science and Research 2016;5(10):388-90.

8. Ambawade VD, Gawai AR, Kate MS. Plemorphiclipoma - A cytologic diagnostic dilemma. National Journal of Laboratory Medicine 2013;2(2):18-20

9. Lin XY, Wang Y, Liu Y, Sun Y, Miao Y, Zhang $\mathrm{Y}$ et al. Pleomorphic lipoma lacking mature fat component in extensive myxoidstroma; a great diagnostic challenge. Diagnostic Pathology 20127: 155 DOI 10.1186/17461596-7-155.

10. Beham A, Schmid C, Hodl S, Fletcher CDM. Spindle cell and pleomorphic lipoma : an immunohistochemical study and histogenetic analysis. J Pathol 1989; 158: 219-22. 